\title{
Preferences and reasons for communicating probabilistic information in verbal or numerical terms
}

\author{
THOMAS S. WALLSTEN \\ University of North Carolina, Chapel Hill, North Carolina \\ DAVID V. BUDESCU \\ University of Illinois, Champaign, Illinois \\ RAMI ZWICK \\ Pennsylvania State University, University Park, Pennsylvania \\ and \\ STEVEN M. KEMP \\ University of North Carolina, Chapel Hill, North Carolina
}

\begin{abstract}
Despite much disagreement regarding how probabilistic information is best communicated, virtually no research has been done to determine what communication modes people prefer or what factors affect their communication preferences. To address these issues, we did a survey of 442 graduate and undergraduate students in several specialties and universities. Some group differences emerged, but overall, 34\% expressed preference for both conveying and receiving information about uncertainty in numerical rather than verbal form, $30 \%$ expressed the opposite preferences, and $35 \%$ indicated that they preferred to receive such information numerically but to convey it verbally. Generally, respondents who endorsed the use of verbal information said that it is easier to use, as well as more natural and personal. Those preferring numerical information said that it is more precise. Virtually all respondents, however, evidenced a willingness to use the opposite of their initially preferred mode if the situation should warrant it. The willingness to switch from one mode to another was said to depend on the level of precision implied by the data and the importance of the issue, as was suggested by Budescu and Wallsten (1987). These results may be helpful in structuring risk communication strategies.
\end{abstract}

The importance of risk communication has increased dramatically in recent years as the public has become more aware of and interested in environmental and medical issues that affect individuals and society. Although much has been written about the best modes for communicating with individuals about uncertainty, little research has been aimed at determining what modes people prefer or what factors affect their preferences. We present survey results relevant to these questions.

To set the stage, we will review the issues very briefly. Although decision and risk analysis are frequently done in terms of estimated or judged probabilities (Morgan \& Henrion, 1990; von Winterfeldt \& Edwards, 1986), the risk communication literature is virtually unanimous in stating that the presentation of statistical information alone is insufficient for communicating with the public (Fisher, 1991; Linnerooth-Bayer \& Wahlströom, 1991; National

This research was supported by National Science Foundation Grants BNS8608692 and BNS8908554. We thank Ann Fisher and Baruch Fischhoff for comments on an earlier draft. R.Z. is in the Department of Marketing at Pennsylvania State. Correspondence should be addressed to T. S. Wallsten, Department of Psychology, University of North Carolina, Chapel Hill, NC 27599-3270.
Research Council, 1981; Slovic, 1986) or even for experts' communications to decision makers (Ruckelshaus, 1984). For example, The National Research Council (1981) wrote that

It is usually dangerous for messages to characterize the overall level of uncertainty quantitatively, as might be done by describing statistical confidence intervals. In most situations expert assessments have multiple sources of uncertainty, and statistical measures do not adequately represent the complexity of the analysis. (p. 171)

However, although authors agree that probabilities and confidence intervals generally do not serve communication, they display much less of a consensus on how uncertainty estimates should be conveyed, and they provide a wide variety of recommendations. Two important issues in the debate are (1) how people use and understand numerical and verbal representations of uncertainty, and (2) the conditions that affect their preference for the use of each. We have some knowledge regarding the former question, but very little regarding the latter.

With respect to use and understanding, the argument at one extreme has been for the supremacy of numerical 
information. For example, Behn and Vaupel (1982) wrote that "ambiguous probability statements are useless. They simply do not provide the information necessary to analyze a decision" (p. 78).

Despite any possible advantages of numerical communications, people (including experts) frequently use vague verbal terms in issuing forecasts or describing opinions regarding uncertain events. Various reasons for this tendency have been offered in the psychological literature (Beyth-Marom, 1982; Budescu \& Wallsten, 1985, 1987; Zimmer, 1983; Zwick \& Wallsten, 1989). It has been speculated that verbal terms are sometimes favored because they seem more natural, are easier to use and understand, and reflect the degree of precision in the communicator's opinion. Kuipers, Moskowitz, and Kassirer (1988) have shown that, in a medical decision context, experienced physicians represented and manipulated likelihoods in verbal rather than numerical form.

Our research has shown that linguistic probability expressions are used consistently by individuals (Budescu \& Wallsten, 1985), that they can be described reliably and validly by means of membership functions (Wallsten, Budescu, Rapoport, Zwick, \& Forsyth, 1986), and that they can serve individuals well in various decision situations (see references in Wallsten, 1990). However, it is also true that individual differences in the use and interpretation of these terms are large (Beyth-Marom, 1982; Budescu \& Wallsten, 1985; Johnson, 1973). On the basis of competing views and findings, we have suggested that

the decision-making process is best served when uncertainty is communicated as precisely as possible, but no more precisely than warranted. When probability estimates are justified by the information, people are capable of providing them in a reliable manner that generally conforms to the axioms of probability theory. However, the more vague is the individual's opinion, the less well is it represented by means of unique probabilities. There exist both numerical and nonnumerical means for expressing vague uncertainties. Each class of methods appears to have advantages and disadvantages, but much research remains to be done with respect to both. (Budescu \& Wallsten, 1987, p. 78)

Despite our knowledge of how and how well people use numerical and verbal probability expressions, we have little systematic information regarding relative preferences for the two modes of expression and factors that may affect those preferences. In this paper, we present the results of a short survey in which respondents were asked directly about their preferences for verbal and numerical probability communications.

\section{METHOD}

\section{The Survey}

The survey consisted of the five questions shown in Table 1. Questions $2 \mathrm{~A}$ and $3 \mathrm{~A}$ were followed by the prompt "Why?" with blank space for the respondent to provide reasons for his/her answer. Questions 2B and 3B were followed by the prompt "If yes, please describe briefly," followed by additional blank space. The questions were prefaced by a brief statement reminding respondents that in daily life uncertainty can be described and communicated either verbally or numerically. They were told that the questions refer to their "feelings, attitudes and preferences regarding the two modes of communicating uncertainty."

\section{Respondents}

Four groups, totaling 442 individuals, were polled. Group UNC consisted of a panel of 95 undergraduate students at the University of North Carolina at Chapel Hill who completed the questionnaire as part of a computer-administered series of surveys on various topics. These students were paid an hourly wage to answer an assortment of questionnaires over the course of a semester. Group MSN consisted of 31 students beginning their second year in the Master of Science in Nursing Program at the University of North Carolina at Chapel Hill. All were enrolled in a statistics course and voluntarily completed the survey after a class period. (Four students in the course elected not to respond.) Group EXP consisted of 55 graduate and undergraduate students who had served as paid subjects in some of our experiments on judgment and decision making with numerical and verbal probabilities. Twenty-three members of this group were students at the University of North Carolina at Chapel Hill, and 32 were students at the University of Haifa in Israel (but all were native English speakers). People in this group answered the questionnaire immediately after they had completed their experimental task. Finally, Group MBA consisted of 255 MBA students at the Graduate School of Industrial Administration at Carnegie Mellon University who answered the questionnaire during their statistics class. A very small, but uncounted number of students in the class did not participate.

Although we did not consistently record ages or background information, members of Groups MSN and MBA differed from those of Group UNC in various ways. The former were all enrolled in introductory graduate statistics classes and tended to be older and more experienced in thinking about issues of uncertainty, owing to their courses of study and professional fields. (Many members of Groups MSN and MBA had worked for a number of years following their undergraduate degree and prior to their Master's programs.) The members of Group EXP varied widely in age and backgrounds, being graduate and undergraduate students in the United States and Israel. They had in common only the experience of having just participated in a study involving verbal and numerical probability expressions.

\section{RESULTS}

Table 1 presents the actual questions along with the total number and distribution of responses to each, combined across all groups. Although overall $77 \%$ of the respondents to Question 1 think most people prefer the verbal mode to communicate uncertainty, the difference among the four groups is statistically significant $\left[\chi^{2}(3)\right.$ $=14.7, p<.05]$. Specifically, a large majority of the

Table 1

The Questionnaire and the Responses

\begin{tabular}{|c|c|c|c|c|c|c|}
\hline & Question & $n$ & Numerical & Verbal & Yes & No \\
\hline 1. & In your opinion, which mode is usually preferred by most people in everyday life? & 442 & $23 \%$ & $77 \%$ & & \\
\hline $2 \mathrm{~A}$. & $\begin{array}{l}\text { When you depend on other people's judgments of uncertainty, how do you usually prefer that they } \\
\text { be communicated to you? }\end{array}$ & 442 & $70 \%$ & $30 \%$ & & \\
\hline 2B. & Are there circumstances under which you prefer the opposite mode from the one you circled above? & 442 & & & $93 \%$ & $7 \%$ \\
\hline $3 \mathrm{~A}$. & Which mode do you usually prefer to use when communicating your opinion to others? & 408 & $35 \%$ & $65 \%$ & & \\
\hline 3B. & Are there circumstances in which you prefer using the opposite mode from the one you circled above? & 408 & & & $85 \%$ & $15 \%$ \\
\hline
\end{tabular}


respondents in Groups UNC (84\%), MBA (75\%), and EXP $(75 \%)$ believe the verbal mode to be generally preferred, but only $52 \%$ of those in Group MSN do so.

Overall, the responses to Questions $2 \mathrm{~A}$ and $3 \mathrm{~A}$ suggest that most people prefer to receive probability communications numerically and to provide them verbally. However, the joint distribution of responses to Questions 2A and 3A shows a somewhat different and more complex pattern of preferences for conveying and receiving information. The results are presented in Table 2 for each group. Note that overall about one third of the respondents prefer numerical $(\mathrm{N})$ communication exclusively, about one third prefer verbal (V) exclusively, and about one third prefer receiving information numerically but conveying it verbally. The contrasting inconsistent pattern is very rare. The differences among the samples are significant $\left[\chi^{2}(9)=67.0, p<.05\right]$, even when the rare VN pattern is dropped from the analysis $\left[\chi^{2}(6)=65.7\right.$, $p<.05]$. Groups MSN and EXP show approximately the same pattern as the overall one, but a majority of Group UNC (61\%) and a minority of Group MBA (17\%) prefer dealing only with words. Conversely, $15 \%$ of Group UNC and $43 \%$ of group MBA express an exclusive preference for numbers.

Referring back to Questions 2B and 3B in Table 1, the vast majority of respondents agree that under certain circumstances they would switch their preferences for transmitting or receiving information. This willingness to exchange modes as a function of circumstances does not depend on the original preference or the group.

Why do people prefer one mode of communication over another and why are they willing to switch? A sufficient number of respondents answered the "Why?" part of Questions 2A, 2B, 3A, and 3B to make a content analysis of the reasons meaningful. After an initial perusal of the replies, five categories were identified for the existence of the usual preferences and four were identified as reasons for switching. In addition, there were a "Don't know" and an "Other" category in each case. The latter was for idiosyncratic responses that occurred too infrequently to categorize. The coding was done by two independent judges who reached a $70 \%$ agreement rate.

Table 2

Joint Preferences for Receiving and

Communicating Information by Sample

Preferred Mode

of Communication

\begin{tabular}{|c|c|c|c|c|c|c|c|c|c|c|c|}
\hline $2 A^{*}$ & $3 A^{*}$ & UNC & $\%$ & MSN & $\%$ & EXP & $\%$ & MBA & $\%$ & Tota & $\%$ \\
\hline $\mathbf{N}$ & $\mathbf{N}$ & 14 & 15 & 10 & 32 & 18 & 33 & 96 & 43 & 138 & 34 \\
\hline V & V & 58 & 61 & 11 & 35 & 15 & 27 & 38 & 17 & 122 & 30 \\
\hline $\mathbf{N}$ & V & 21 & 22 & 10 & 32 & 22 & 40 & 88 & 39 & 141 & 35 \\
\hline V & $\mathbf{N}$ & 2 & 2 & 0 & 0 & 0 & 0 & 3 & 1 & 5 & 1 \\
\hline Total & & 95 & 100 & 31 & 100 & 55 & 100 & 225 & 100 & 406 & 100 \\
\hline
\end{tabular}

Note-N, numerical; V, verbal; UNC, University of North Carolina undergraduates; MSN, 2nd-year master's degree nursing students, University of North Carolina; EXP, experienced graduate and undergraduate student subjects from the University of North Carolina and the University of Haifa; MBA, graduate MBA students at Carnegie Mellon University. *Question.
Table 3

Content Analysis of Reasons for Communication Preferences

\begin{tabular}{lccccc}
\hline & \multicolumn{2}{c}{ From Others } & & \multicolumn{2}{c}{ To Others } \\
\cline { 2 - 3 } \cline { 5 - 6 } \cline { 5 - 6 } & Numerical & Verbal & & Numerical & Verbal \\
\hline & \multicolumn{2}{c}{ Usual Preferences } & & \\
More precise & $75.6 \%$ & $3.8 \%$ & & $51.7 \%$ & $1.1 \%$ \\
More personal & $6.1 \%$ & $17.4 \%$ & & $10.3 \%$ & $14.9 \%$ \\
More natural & $2.9 \%$ & $37.1 \%$ & & $3.4 \%$ & $24.5 \%$ \\
Easier & $2.9 \%$ & $17.4 \%$ & & $7.6 \%$ & $29.7 \%$ \\
More credible & $3.2 \%$ & $5.3 \%$ & & $6.9 \%$ & $2.2 \%$ \\
Don't know & $0.6 \%$ & $4.5 \%$ & & $6.2 \%$ & $6.7 \%$ \\
Other & $8.7 \%$ & $14.4 \%$ & & $13.8 \%$ & $20.8 \%$ \\
$n$ & 312 & 132 & & 145 & 269 \\
& & & & \\
Issue unimportant & $0.0 \%$ & $20.8 \%$ & & $0.0 \%$ & $21.6 \%$ \\
Information unreliable & $0.9 \%$ & $10.7 \%$ & & $0.9 \%$ & $19.2 \%$ \\
Issue important & $10.5 \%$ & $1.0 \%$ & & $9.7 \%$ & $0.0 \%$ \\
Precision possible & $21.9 \%$ & $0.7 \%$ & & $35.0 \%$ & $0.0 \%$ \\
Don't know & $14.9 \%$ & $32.6 \%$ & & $15.0 \%$ & $30.4 \%$ \\
Other & $51.8 \%$ & $34.2 \%$ & & $39.4 \%$ & $28.8 \%$ \\
$n$ & 114 & 298 & & 226 & 125 \\
\hline
\end{tabular}

Note-Vaues other than $n$ represent percent responses for each category.

Table 3 presents the categories, the total number $(n)$ of respondents who provided a reason for each preference, and the percentage breakdown into the categories of the reasons offered. The percentages are the means of the separate percentages determined by the two independent judges. In interpreting the table, keep in mind that individuals falling in the Numerical column under Usual Preferences fall in the Verbal column under Opposite Mode, and conversely. The first point of interest is that all the reasons given for the usual preferences refer to the nature of the communication-it is more precise, easier, more natural, or more credible-whereas the reasons given for switching to the opposite mode all refer to the issue, which is important or unimportant, or to the information base, which is unreliable or allows precision. Second, "Don't know" and idiosyncratic "Other" responses were much more frequently given to the question of why switch than to the question of why have the primary preference.

People selecting numerical as their usual preference for either receiving or conveying information generally cited the precision of that mode as their reason, whereas those selecting verbal tended to say that it was easier, more natural, or more personal. Fewer people were able to verbalize their reasons for being able to switch. But of the remaining respondents, the modal reasons of those who initially preferred the numerical mode were that the verbal mode was preferable when the issue was unimportant or the information unreliable, and of those who initially had the opposite inclination, the reasons were that the numerical mode was preferable when the issue was important or precision was possible.

\section{DISCUSSION}

The four groups of respondents differed in various ways; collectively, they can be taken to have represented a wide spectrum of individuals. In this light, perhaps one 
should be more impressed with the group similarities than with any differences. Collectively, the survey responses indicate a general initial preference for receiving information numerically and for conveying it verbally. The UNC group displayed the greatest initial preference for the verbal mode and the least for the numerical; the opposite was true for the MBA group. Questionnaire results similar to the overall pattern have been obtained by Brun and Teigen (1988). The pattern has also been substantiated in an experiment done by Erev and Cohen (1990), in which individuals were required to convey or receive probabilistic information for the purpose of decision making with real money rewards. Most communication preferences in this context were to provide judgments verbally but to receive them numerically.

Perhaps of greatest interest, however, is our respondents' flexibility in communicating about uncertainty as a function of the nature of the issue and the strength of the data. Generally, people indicated a preference for numerical communication when the situation was important or when numerical estimates were supported by the information base. In contrast, they preferred verbal communication when the situation was unimportant or the information base weak.

Thus, all other things being equal, in communications to the public, primarily verbal communication might be most effective with groups similar to UNC and primarily numerical ones might be most effective with groups like MBA. But clearly, communications are best structured according to the available information and the nature of the issue (as has been suggested by Budescu \& Wallsten, 1987). Similarly, questionnaires designed to probe individuals' perceptions of risk probabilities should be structured with the particular group in mind. But since it is unlikely that target groups will have specific data at hand, judgments should probably be elicited in verbal form whenever possible. This apparently was De March's (1991) strategy in assessing area residents' probabilities of a nearby industrial emergency.

Finally, it is worth noting that the survey actually supports proponents of each mode for communicating probabilistic information. Regardless of the direction of communication, current respondents preferring the numerical mode cited its precision (as advocated by decision analysts; see Behn \& Vaupel, 1982; von Winterfeldt \& Edwards, 1986) and those preferring the verbal mode cited its ease (Beyth-Marom, 1982; Budescu \& Wallsten, 1987; Zimmer, 1983; Zwick \& Wallsten, 1989).

Often, some combination of verbal and numerical description is required to convey the complexity of an analysis or the degree of confidence in the results. The present survey may provide some guidance for deciding how to mix the two modes of communication when one is directing messages to, or soliciting opinions from, particular groups about risk estimates based on differing degrees of support.

\section{REFERENCES}

BeHN, R. D., \& VAUPEL, J. W. (1982). Quick analysis for busy decision makers. New York: Basic Books.

BEYTh-Marom, R. (1982). How probable is probable? A numerical translation of verbal probability expressions. Journal of Forecasting, 1, 257-269.

Brun, W., \& Teigen, K. H. (1988). Verbal probabilities: Ambiguous, context dependent, or both. Organizational Behavior \& Human Decision Processes, 41, 390-404.

Budescu, D. V., \& Wallsten, T. S. (1985). Consistency in interpretation of probabilistic phrases. Organizational Behavior \& Human Decision Processes, 36, 391-405.

Budescu, D. V., \& Wallsten, T. S. (1987). Subjective estimation of vague and precise uncertainties. In G. Wright \& P. Ayton (Eds.), Judgmental forecasting (pp. 63-82). New York: Wiley.

De March, B. (1991). The Seveso Directive: An Italian pilot study in enabling communication. Risk Analysis, 11, 207-237.

EREv, I., \& CoHEN, B. (1990). Verbal versus numerical probabilities: Efficiency, biases, and the preference paradox. Organizational Behavior \& Human Decision Processes, 45, 1-18.

FISHER, A. (1991). Risk communication challenges. Risk Analysis, 11, 173-183.

JoHNson, E. M. (1973). Numerical encoding of qualitative expressions of uncertainty (Tech paper 250). Alexandria, VA: US Army Research Institute for the Behavioral and Social Sciences.

Kuipers, B., Moskowitz, A. J., \& Kassirer, J. P. (1988). Critical decisions under uncertainty: Representation and structure. Cognitive Science, 12, 177-210.

LiNNEROOTh-BAyER, J., \& WAhlström, B. (1991). Applications of probabilistic risk assessments: The selection of appropriate tools. Risk Analysis, 11, 239-248.

Morgan, M. G., \& Henrion, M. (1990). Uncertainty: A guide to dealing with uncertainty in quantitative risk and policy analysis. New York: Cambridge University Press.

National Research Council Governing Board Committee on the AssESSMENT OF RISK (1981). The handling of risk assessments in NRC reports. Washington, DC: US National Research Council.

Ruckelshaus, W. D. (1984). Risk in a free society. Risk Analysis, 4, 157-162.

SLOvic, P. (1986). Informing and educating the public about risk. Risk Analysis, 6, 403-415.

VON WINTERFELDT, D., \& EDWARDS, W. (1986). Decision analysis and behavioral research. New York: Cambridge University Press.

WALLSTEN, T. S. (1990). The costs and benefits of vague information. In R. Hogarth (Ed.), Insights in decision making: A tribute to the late Hillel Einhorn (pp. 28-43). Chicago: University of Chicago Press.

WAllsten, T. S., Budescu, D. V., RAPOPORT A., ZWick, R., \& ForSYTH, B. (1986). Measuring the vague meanings of probability terms. Journal of Experimental Psychology: General, 115, 348-365.

Zimmer, A. C. (1983). Verbal vs. numerical processing of subjective probabilities. In R. W. Scholz (Ed.), Decision making under uncertainty (pp. 159-182). New York: North-Holland.

ZWICK, R., \& WALLSTEN, T. S. (1989). Combining stochastic and linguistic inexactness: Theory and experimental evaluation of four fuzzy probability models. International Journal of Man-Machine Studies, 30, 69-111. 